\title{
A Novel HTS PM Vernier Motor for Direct-Drive Propulsion
}

\author{
Jiangui Li, Student Member, IEEE, and K. T. Chau, Senior Member, IEEE
}

\begin{abstract}
In this paper, a novel high-temperature superconductor (HTS) permanent magnet (PM) vernier motor is proposed for direct-drive propulsion, which can directly offer the low-speed high-torque capability and the high-speed rotating field design to eliminate the gearing mechanism and maximize the power density, respectively. The key is to newly introduce HTS bulks to flux-modulation poles that can effectively modulate between the high-speed rotating field of armature windings and the low-speed rotating field of the PM outer rotor. Also, the use of HTS bulks can greatly reduce the flux leakage and hence improve the torque density. Based on using the finite element method, the motor performances are analysed. Hence, the validity of the proposed motor is verified.
\end{abstract}

Index Terms-Direct-drive, finite element method, high-temperature superconductor, permanent magnet, vernier machine.

\section{INTRODUCTION}

$\mathbf{T}$ HE discovery of high-temperature superconductor (HTS) superconducting at temperatures above $77 \mathrm{~K}$ in 1986 has made the HTS machines less expensive and more practical [1]. In recent years, various HTS machines have been developed for various applications, such as the aircraft propulsion [2], ship propulsion [3], and wind power generation [4]. They include the axial-flux machine [5], reluctance machine [6], and linear machine [7]. However, for those direct-drive applications such as the electric vehicle propulsion, the motor needs to operate at low frequencies to create the low-speed rotating field and hence motion. Such low-frequency machine design will inevitably increase the motor size and weight. Alternatively, the motor can adopt the high-frequency machine design to achieve compact size and lightweight, but needs to incorporate a mechanical gear or magnetic gear [8] to scale down the rotating speed. However, an additional gear will definitely increase the cost and complexity of the whole drive system.

Recently, the permanent magnet (PM) vernier machine has been developed for direct-drive application [9]. This machine utilizes the vernier concept to directly convert a high-speed rotating field to a low-speed rotating motion. Fig. 1 shows an outer-rotor configuration of a conventional PM vernier motor. As depicted, the key is the introduction of flux-modulation poles that function to modulate the high-speed rotating field generated by armature windings to the low-speed rotating field in the

Manuscript received August 02, 2010; accepted October 03, 2010. Date of publication November 09, 2010; date of current version May 27, 2011. . This work was supported by a grant (Project No. HKU 710710E) from the Research Grants Council, Hong Kong Special Administrative Region, China.

The authors are with the Department of Electrical and Electronic Engineering, The University of Hong Kong, Hong Kong (e-mail: jgli@eee.hku.hk).

Color versions of one or more of the figures in this paper are available online at http://ieeexplore.ieee.org.

Digital Object Identifier 10.1109/TASC.2010.2085412

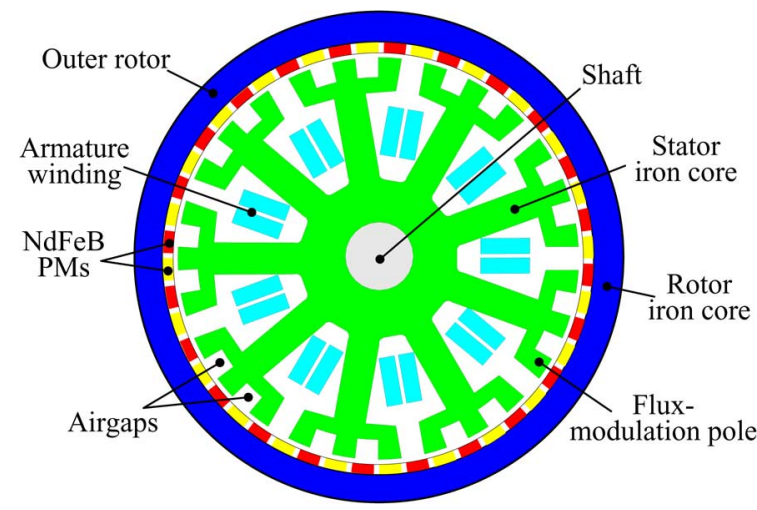

Fig. 1. Configuration of conventional PM vernier motor.

airgap. This low-speed rotating airgap field in turn interacts with the PM poles surface-mounted on the outer rotor, hence creating the desired low-speed high-torque rotation. So, this PM vernier motor can simultaneously possess the high-speed rotating field design and low-speed high-torque direct-drive capability, thus offering high power density while eliminating the undesirable transmission mechanism.

In order to further improve the power density for high-power application, a HTS PM vernier machine has recently been proposed, which utilizes the yttrium barium copper oxide (YBCO) material for the armature windings [10]. However, since the YBCO tape is quite brittle, it causes difficulty in manufacture, which will significantly degrade its practicability. Also, the fluxmodulation poles of the machine make it difficult to embed the HTS armature windings into the stator inner slots.

On the other hand, the PM vernier motor suffers from a problem that there is serious flux leakage in the airgap nearby the flux-modulation poles. This flux leakage will significantly degrade its torque density for direct-drive propulsion.

The purpose of this paper is to propose a novel HTS PM vernier motor for direct-drive propulsion. Instead of using the HTS material for the armature windings, the proposed motor newly incorporates HTS bulks that are inset on the surface of the stator. Thus, the flux-shielding effect of HTS bulks can be artfully utilized to serve as the flux-modulation poles.

\section{Motor DeSIGN}

\section{A. Configuration}

The configuration of the proposed HTS PM vernier motor is shown in Fig. 2. It adopts an outer-rotor arrangement, in which there are the conventional 3-phase armature copper windings wound in the inner slots of the stator, HTS bulks inset on the surface of the flux-modulation poles of the stator, and neodymium 


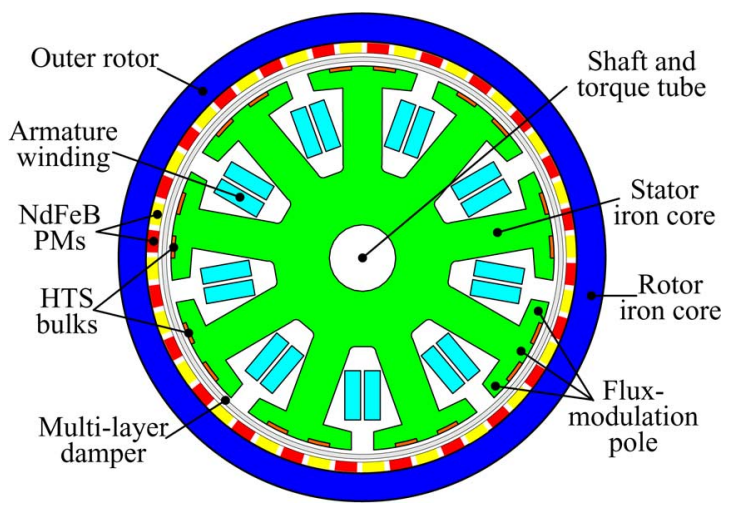

Fig. 2. Configuration of proposed HTS PM vernier motor.

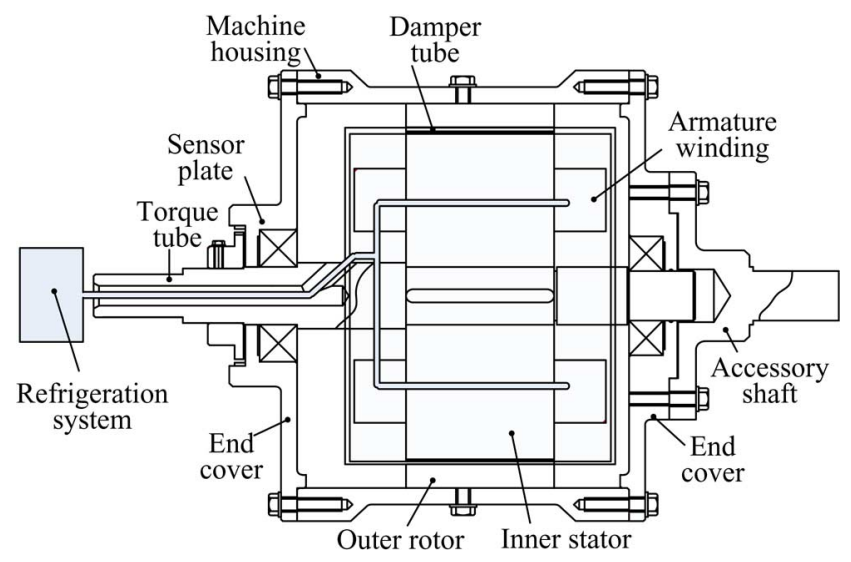

Fig. 3. Realization of proposed HTS PM vernier machine.

iron boron $(\mathrm{NdFeB}) \mathrm{PMs}$ mounted on the inner surface of the outer rotor.

Because of the flux-shielding feature of HTS bulks, they can be simply inset on the stator surface to provide flux guiding which resembles to the presence of the flux-modulation poles. They function to modulate the high-speed rotating field in the inner part of the stator to become the low-speed rotating field in the airgap which in turn synchronously rotates with the PMs mounted on the outer rotor. Compared with the use of slotting, the use of HTS bulks can offer two distinct advantages for flux modulation. Firstly, with the use of HTS bulks, more space of the stator can be utilized for the iron core or the armature windings, hence reducing the magnetic saturation or increasing the overall electric loading. Secondly, it can virtually eliminate the flux leakage around the flux-modulation poles, hence improving the torque production and hence torque density.

\section{B. Realization}

The realization of the proposed HTS PM vernier motor is shown in Fig. 3. The key for realization is how to enable proper cooling for the HTS bulks. The adopted HTS bulks are based on the 2nd generation YBCO material [11]. They are refrigerated by circulated liquid nitrogen that is led in through cooling channels by pipes. The operating temperature is regulated at around $77 \mathrm{~K}$. The cooling channels are located between the small apertures around the HTS bulks in the stator.

Since the PMs are mounted on the inner surface of the outer rotor, they should be kept away from the liquid nitrogen. If the PMs are cooled to below $135 \mathrm{~K}$, their magnetization will no longer be uniaxial. Thus, a multi-layer damper tube is adopted to embrace the stator so that the PMs do not have direct contact with the liquid nitrogen. This damper tube also acts as a magnetic shield to alleviate the eddy-current loss in the PMs. Additionally, the damper tube can function to reduce the non-periodical vibration of the outer rotor, and to diminish the influence of the magnetic field generated by the outer rotor on the YBCO bulks inset on the stator surface.

Different from conventional motors that the driving torque is transmitted to the mechanical load via the shaft, the proposed motor employs a torque tube to transmit the driving torque. This torque tube has a thin wall that can effectively suppress the heat transfer between the motor and the surroundings, hence minimizing the energy consumption for refrigeration.

In order to decrease the eddy-current loss in the iron core, the stator core is laminated with sheets of $0.5 \mathrm{~mm}$. The corresponding stacking factor is 0.95 . Since both the stator and rotor adopt the iron core, the airgap length can be minimized so that the required ampere-turns are greatly reduced.

\section{PRINCIPLE OF OPERATION}

The principle of operation of the proposed HTS PM vernier motor is similar to that of the coaxial magnetic gear [8]. So, in order to utilize the vernier effect, it needs to satisfy the following relationship:

$$
p_{r}=N_{s}-p_{s}
$$

where $N_{s}$ is the number of HTS flux-modulation poles, $p_{r}$ is the number of rotor pole-pairs and $p_{s}$ is the number of stator polepairs. As aforementioned, the high-speed rotating field in the inner part of the stator is modulated into the low-speed rotating field in the airgap, which in turn synchronously rotates with the PM outer rotor. The corresponding speed reduction ratio $G_{r}$ is given by:

$$
G_{r}=\left(m p_{s}+k N_{s}\right) /\left(m p_{s}\right)
$$

where $m=1,3, \cdots$ and $k=0, \pm 1, \pm 2, \ldots$ The combination of $m=1$ and $k=-1$ is selected since it yields the highest asynchronous space harmonic and hence the torque production.

In this design, there are 9 slots in the stator, which are occupied by the 3-phase armature windings with 6 poles $\left(p_{s}=\right.$ $3)$. Each stator tooth is split into 3 flux-modulation poles by using the HTS bulks, thus constituting totally 27 flux-modulation poles $\left(N_{s}=27\right)$. From (1), $p_{r}=24$ is resulted, which denotes that there are $48 \mathrm{PM}$ poles mounting on the outer rotor. From (2), it yields $G_{r}=-8: 1$, where the minus sign indicates that the two rotating fields are of opposite directions. Hence, the output torque of the proposed motor is 8 times that of a conventional PM motor with the same number of armature winding pole-pairs. Some key data of the proposed motor are listed in Table I.

\section{Motor AnALYSIS}

The performances of the proposed HTS PM vernier motor are analyzed by using the finite element method (FEM). In order to take into account magnetic saturation during analysis, the permeability of stator and rotor iron cores is based on the practical data of iron material. On the other hand, the permeability of PMs is a constant based on the NdFeB material, while the permeability of HTS bulks is set to zero. 
TABLE I

KEY DATA OF PROPOSED HTS PM VERNIER MOTOR

\begin{tabular}{ll}
\hline \hline Rated output power & $1 \mathrm{~kW}$ \\
Rated input power & $1.25 \mathrm{~kW}$ \\
Rated frequency & $50 \mathrm{~Hz}$ \\
Rated speed & $125 \mathrm{rpm}$ \\
No. of pole-pairs in rotor & 24 \\
No. of pole-pairs in stator & 3 \\
No. of HTS flux-modulation poles & 27 \\
Outside diameter of rotor & $240 \mathrm{~mm}$ \\
Length of airgap & $2 \mathrm{~mm}$ \\
Outside diameter of stator & $197 \mathrm{~mm}$ \\
Axial length & $60 \mathrm{~mm}$ \\
HTS material & YBCO \\
PM material & $\mathrm{NdFeB}$ \\
\hline \hline
\end{tabular}
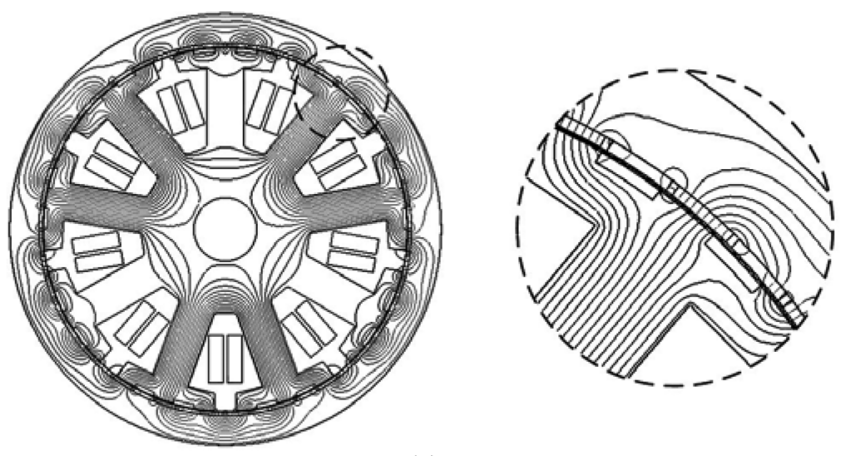

(a)
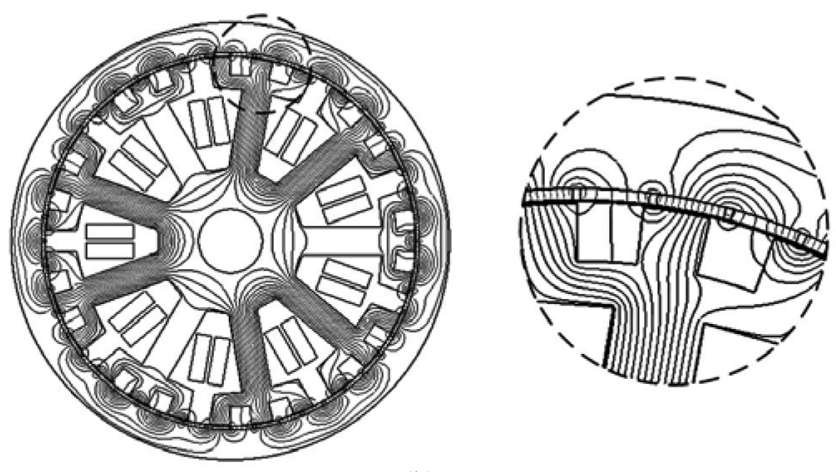

(b)

Fig. 4. Magnetic field distributions: (a) with HTS; (b) without HTS.

The proposed motor is quantitatively compared with its conventional counterpart. For a fair comparison, both motors adopt the same outside diameter and axial length as well as the same input power, while allowing for optimal internal design. So, by using the HTS bulks instead of the conventional flux-modulation poles, the internal space can be saved, leading to allow for using a larger stator iron core to accommodate the armature windings.

Firstly, a comparison of magnetic field distributions of the two motors is shown in Fig. 4. It can be observed that the conventional motor suffers from serious flux leakage while the proposed motor does not have significant flux leakage. Also, it can be seen that the flux lines per stator tooth of the proposed motor can evenly pass through the HTS flux-modulation poles, hence confirming the desired flux modulation. Then, the corresponding airgap flux density and the resultant flux linkage waveforms are plotted in Fig. 5. It illustrates that there are 24

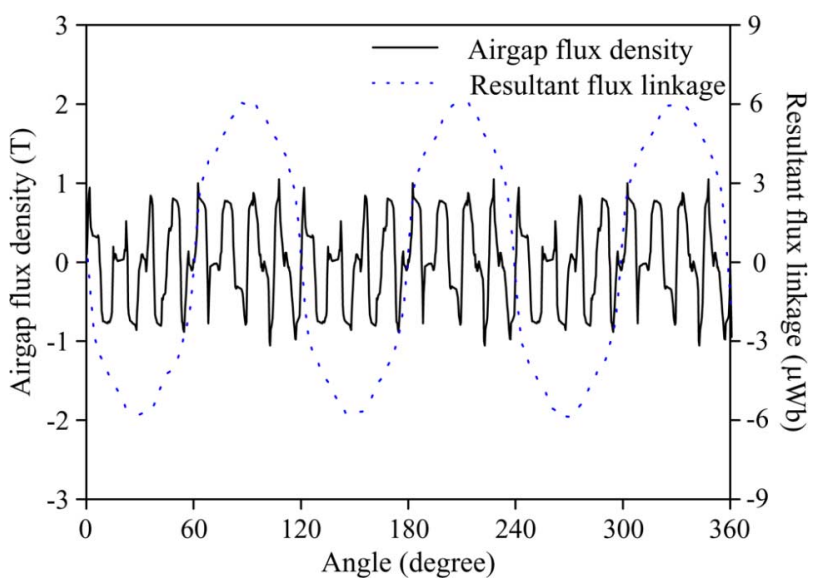

Fig. 5. Airgap flux density and resultant flux linkage waveforms with HTS.
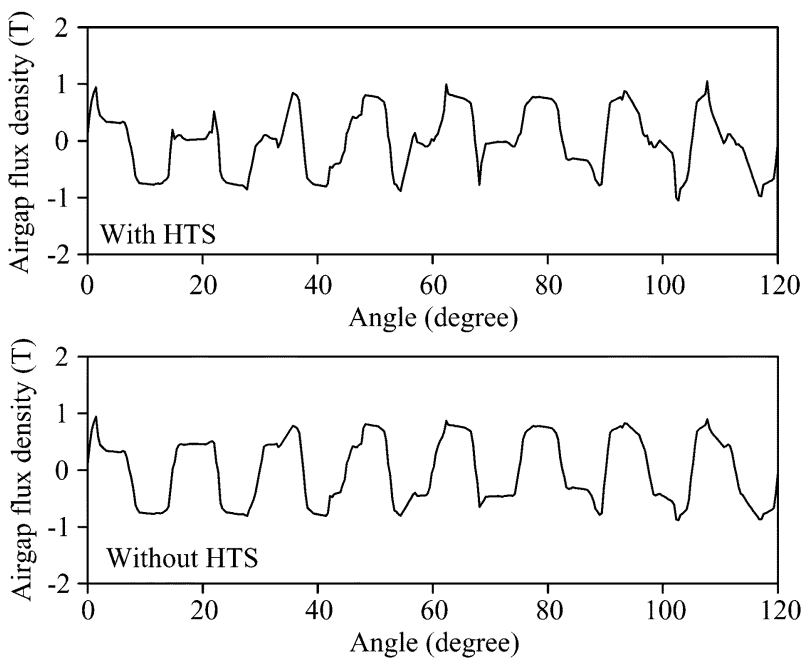

Fig. 6. Airgap flux density waveforms with and without HTS.

pole-pairs in the airgap within $360^{\circ}$ (mechanical degree) which actually correspond to the 24 pole-pairs of the PM rotor, while there are 3 pole-pairs of the resultant flux linkage which correspond to the 3 pole-pairs of the armature windings. Hence, it confirms that the proposed HTS flux-modulation poles can successfully scale down the rotating field speed by 8 times. Moreover, a comparison of airgap flux density waveforms of the two motors is shown in Fig. 6. It depicts that the use of HTS bulks can effectively shield the fringing flux. Also, the corresponding air-gap flux density under the flux-modulation slots is nearly zero while that under the teeth is improved, thus confirming the effectiveness of the HTS bulks.

Secondly, a comparison of 3-phase back electromotive force (EMF) waveforms operating at $125 \mathrm{rpm}$ is shown in Fig. 7. It can be found that the back EMF magnitudes with and without using HTS are respectively $68.8 \mathrm{~V}$ and $42.5 \mathrm{~V}$, which denotes that there is an improvement of $161.9 \%$ due to the use of HTS bulks. It should be noted that the EMF waveforms with HTS are rough comparing to the ones without HTS. The roughness is actually due to the shielding effect of HTS bulks which force all flux lines going through the stator poles and then abruptly to the PMs of the rotor. Thus, the airgap flux density and hence EMF waveforms are improved in terms of magnitude but associated with larger higher-order harmonics. Moreover, Fig. 8 shows 


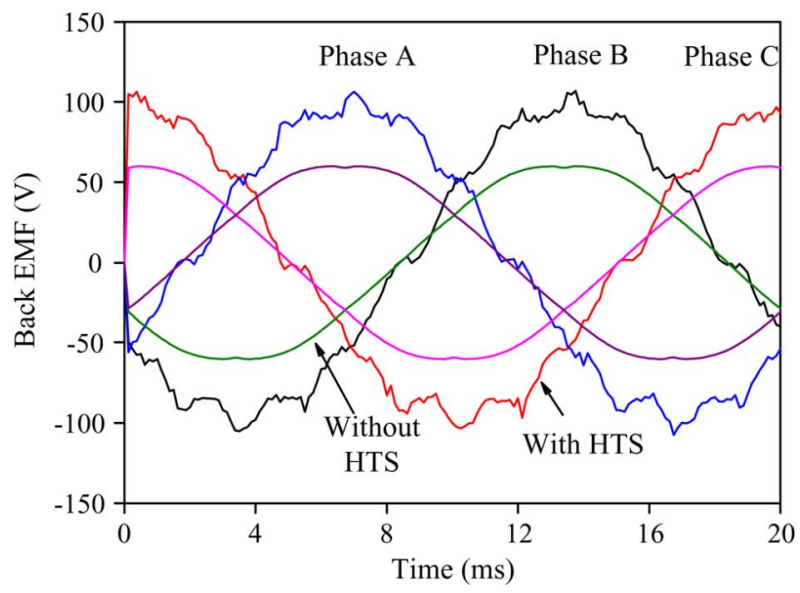

Fig. 7. Back EMF waveforms with and without HTS.

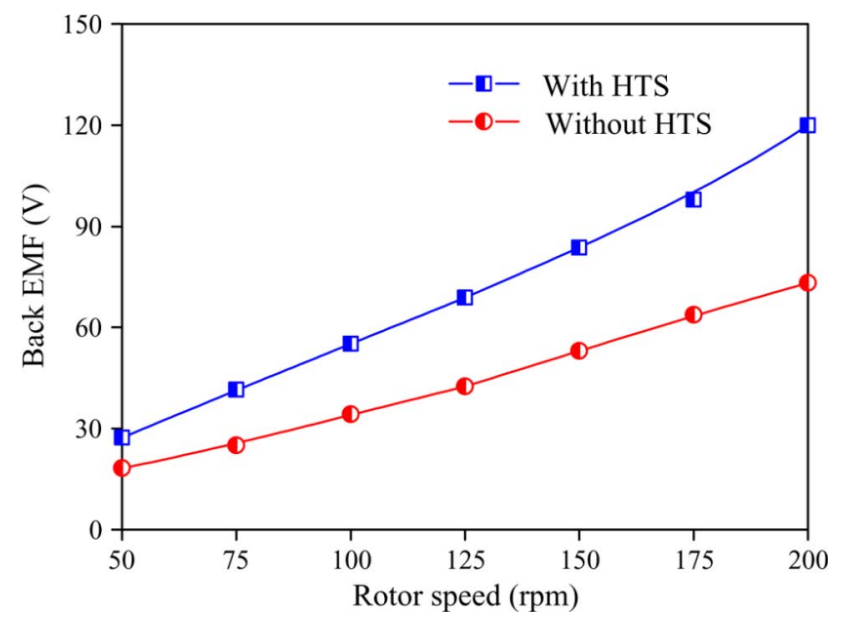

Fig. 8. Back EMF characteristics with and without HTS.

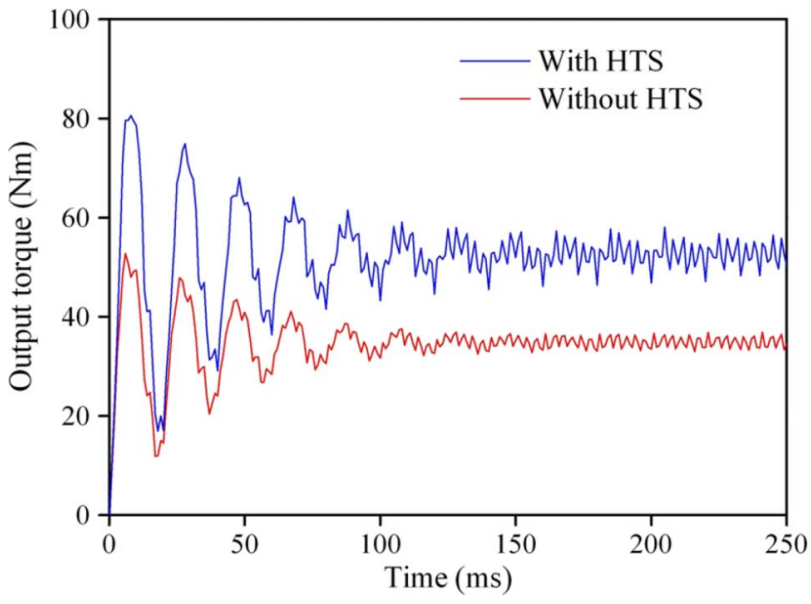

Fig. 9. Output torque waveforms with and without HTS.

their back EMF characteristics under different rotor speeds. As expected, they are linearly proportional to the rotor speed.

Thirdly, a comparison of output torque waveforms operating at $125 \mathrm{rpm}$ is shown in Fig. 9. As expected, with the use of HTS bulks, the proposed motor can offer the steady-state output torque of $52.5 \mathrm{Nm}$, which indicates an improvement of $149.6 \%$.

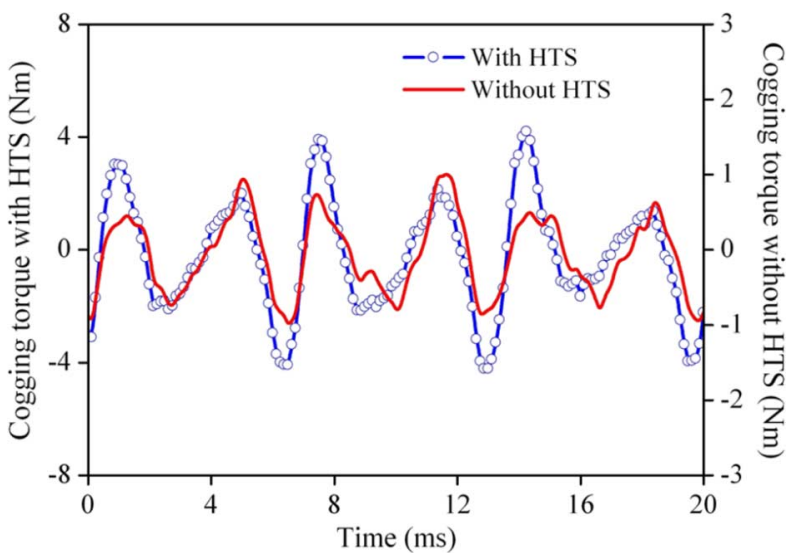

Fig. 10. Cogging torque waveforms with and without HTS.

While the flux-modulation poles provide unique magnetic paths to modulate between the stator field and the rotor field, they inevitably cause different equivalent airgap lengths at different positions, leading to create the cogging torque. Thus, finally, a comparison of cogging forces of the two motors is shown in Fig. 10. It can be observed that with the use of HTS bulks, the peak cogging torque is increased from $1 \mathrm{Nm}$ to 4.2 $\mathrm{Nm}$, which is actually due to the increased value of the variation of magnetic co-energy $\Delta W$ against the angular displacement of the rotor $\Delta \theta$. Nevertheless, after normalized by their respective steady-state output torque, the normalized cogging torque are only $2.8 \%$ and $8 \%$, which are still much lower than that of the conventional PM motors or switched reluctance motors. It is due to the fact that the cogging torque of the proposed motor is governed by the least common multiplier of $N_{s}$ and $p_{r}$. The corresponding large values of $N_{s}$ and $p_{r}$ enable to suppress the cogging torque.

\section{CONCLUSION}

In this paper, a novel HTS PM vernier motor has been proposed for direct-drive propulsion, which can directly offer the low-speed high-torque capability to eliminate the gearing mechanism and the high-speed rotating field design to maximize the power density. This motor possesses a novel HTS flux-modulation pole structure that can greatly reduce the flux leakage and hence improve the torque density. Moreover, the use of outerrotor arrangement with all HTS bulks located in the stator can greatly ease the requirement of refrigeration. By using the FEM, it confirms that the proposed HTS PM vernier motor can significantly improve the back EMF and steady-state output torque.

\section{REFERENCES}

[1] B. Gamble, G. Snitchler, and S. S. Kalsi, "HTS generator topologies," in IEEE Power Eng. Soc. General Meeting, 2006, pp. 1-5.

[2] P. J. Masson, M. Breschi, P. Tixador, and C. A. Luongo, "Design of HTS axial flux motor for aircraft propulsion," IEEE Trans. Appl. Supercond., vol. 17, no. 2, pp. 1533-1536, 2007.

[3] S. Woodruff, H. Boenig, F. Bogdan, T. Fikse, L. Petersen, M. Sloderbeck, G. Snitchler, and M. Steurer, "Testing a 5 MW high-temperature superconducting propulsion motor," in IEEE Elec. Ship Technol. Symposium, 2005, pp. 206-213.

[4] A. B. Abrahamsen, N. Mijatovic, E. Seiler, M. P. Sorensen, M. Koch, P. B. Norgard, N. F. Pedersen, C. Traeholt, N. H. Andersen, and J. Ostergard, "Design study of $10 \mathrm{~kW}$ superconducting generator for wind turbine applications," IEEE Trans. Appl. Supercond., vol. 19, no. 3, pp. 1678-1682, 2009. 
[5] H. Matsuzaki, Y. Kimura, I. Ohtani, M. Izumi, T. Ida, Y. Akita, H. Sugimoto, M. Miki, and M. Kitano, "An axial gap-type HTS bulk synchronous motor excited by pulsed-field magnetization with vortex-type armature copper windings," IEEE Trans. Appl. Supercond., vol. 15, no. 2, pp. 2222-2225, 2005.

[6] M. Qiu, Z. Xu, Z. H. Yao, D. Xia, L. Z. Lin, G. M. Zhang, L. Xiao, H. T. Ren, Y. L. Jiao, and M. H. Zheng, "Design and performance of a small HTS bulk reluctance motor," IEEE Trans. Appl. Supercond., vol. 15 , no. 2 , pp. $1480-1483,2005$.

[7] W. Li and K. T. Chau, "Design and analysis of a novel linear transverse flux permanent magnet motor using HTS magnetic shielding," IEEE Trans. Appl. Supercond., vol. 20, no. 3, pp. 1106-1109, 2010.
[8] L. Jian, K. T. Chau, W. Li, and J. Li, "A novel coaxial magnetic gear using bulk HTS for industrial applications," IEEE Trans. Appl. Supercond., vol. 20, no. 3, pp. 981-984, 2010.

[9] J. Li, K. T. Chau, J. Z. Jiang, C. Liu, and W. Li, "A new efficient permanent-magnet vernier machine for wind power generation," IEEE Trans. Magnetics, vol. 45, no. 6, pp. 1475-1478, 2010.

[10] J. Li and K. T. Chau, "Design and analysis of a HTS vernier PM machine," IEEE Trans. Appl. Supercond., vol. 20, no. 3, pp. 1055-1059, 2010.

[11] Y. Jiang, R. Pei, Z. Hong, Q. Jiang, and T. A. Coombs, "Design of an HTS motor," Journal of Physics: Conf. Series, vol. 97, no. 12123, pp. $1-6,2008$. 